\title{
G. Dahlquist \\ Can we slow the rising incidence of childhood-onset autoimmune diabetes? The overload hypothesis
}

Received: 27 September 2005 / Accepted: 12 October 2005 / Published online: 14 December 2005

(C) Springer-Verlag 2005

\begin{abstract}
Overload of the beta cell, mediated by a variety of mechanisms, may sensitise it to immune damage and apoptosis, and thus accelerate ongoing autoimmune processes leading to its destruction. Environmental risk determinants that may exert such overload effects include insulin resistance due to excess fat cell accumulation, and increased insulin requirement due to a high growth rate, physical stress (infection, inflammation) or psychological stress. The increasing incidence of childhood diabetes, and the shift to younger age at onset, is unlikely to be driven by environmental risk factors that have been associated with initiation of autoimmunity, e.g. virus infections or early infant feeding. Risk factors that may accelerate beta cell destruction have shown a steady increase in the population, and are more plausible causes of such a pattern of change. Child growth, weight and birthweight are well-established estimates of community wealth and increase in most countries of Europe. Overfeeding of children early in life leads to both accelerated growth and weight, and even a moderate excess of child growth, not necessarily associated with obesity, is associated with risk of type 1 diabetes. New, safe and effective immune-modulating drugs for possible arrest of the autoimmune process may become available in time, but in the interim these accelerating factors may be targeted. Public health programmes for pregnant mothers and young families, aiming at changing overfeeding and the sedentary lifestyle of the children would be preferable to other alternatives. Interventions such as these would be safe and could potentially influence future risks of type 1 and type 2 diabetes and other major threats to adult health.
\end{abstract}

Keywords Children · Overfeeding · Overload · Prevention - Type 1 diabetes

\footnotetext{
G. Dahlquist $(\bowtie)$

Department of Clinical Sciences, Paediatrics,

Umea University Hospital,

S-90185 Umea, Sweden

e-mail: gisela.dahlquist@pediatri.umu.se

Tel.: +46-90-7853876

Fax: +46-90-123728
}

Abbreviations GNP: Gross national product

\section{Introduction}

Childhood-onset type 1 diabetes is on the increase in most countries around the world [1-3], with an average annual increase in incidence in European children aged 0-14 years of $3.4 \%$, rising to $6.3 \%$ in the $0-5$ year age group [2]. In Sweden, a nationwide prospective register found no increase in young adults aged 15-34 years, and analysis of cumulative rates indicated a shift towards a younger age of onset rather than an overall rise in type 1 diabetes, at least up to the age of 35 [4]. Similar results were reported from Belgium [5]. A shift towards earlier onset will increase the burden upon patients and their families, and will also result in earlier onset of the complications of the disease, thus affecting the whole of society.

A recent editorial in this journal has argued that the increasing incidence of type 1 diabetes in the young is the result of accelerated disease progression [6]. The focus of interest should therefore shift to accelerating factors rather than potential triggers of autoimmunity. This discussion paper argues that at least part of the changing pattern of type 1 diabetes is preventable and reflects the increased expression of the disease in the childhood population caused by overload of the beta cell early in life, making the beta cell more vulnerable to autoimmune attack and apoptosis. Several risk factors other than obesity that may cause such acceleration have been implicated in epidemiological studies, and experimental studies provide potential mechanisms for these effects. There is therefore a basis for intervention - but the strategies must be safe and efficient.

\section{The natural course of pre-type 1 diabetes}

The past two decades have revealed the complexity of the genetic risk factors involved in type 1 diabetes and the potential for interaction between different genes and the 
environment in causing the disease via autoimmune destruction of the beta cells. Twin studies and descriptive epidemiology have shown that environmental factors have a dominant role in disease expression. Such non-genetic factors may either initiate autoimmunity or accelerate/ precipitate beta cell destruction [7]. Follow-up studies of first-degree relatives of type-1 diabetic patients have shown that autoimmunity often precedes clinical disease by many years [8-10]. Not all individuals that carry autoantibodies towards the beta cells ultimately develop clinical diabetes, and the signs of autoimmunity may disappear [11-13]. Autoantibody prevalence is similar among relatives of type 1 diabetic patients in different countries, despite a wide variation in diabetes incidence [14]. Many authors thus agree that, once autoimmunity has been triggered, the progressive decrease in beta cell function may be caused by subsequent exposure events $[7,15,16]$. Experimental and epidemiological research has to a great extent focused on environmental risk factors that might trigger autoimmunity towards the beta cells, such as viruses [17] and food components, e.g. early introduction to different cows' milk proteins or nitrosamine compounds $[18,19]$. The steadily increasing incidence of type 1 diabetes cannot, however, plausibly be associated with any of the potential triggers or initiators of autoimmunity, which should obviously show a steady pattern of changing exposure in parallel with the incidence trend. Enterovirus infections are not increasing but rather have an epidemic pattern of variability over time, and breast-feeding duration has increased despite increasing diabetes incidence [3].

In summary, studies on the epidemiology and the natural history of the disease support the view that the environmental factors that may cause a steady increase in childhood-onset diabetes and a shift to a younger age at onset operate after the initiation of autoimmunity and act by accelerating or precipitating disease progression.

\section{The overload effect in autoimmune diabetes}

Based on epidemiological studies, we proposed that different environmental risk factors operating after the initial triggering of autoimmunity might accelerate the process by overload effects that may increase the demand for insulin production, such as high growth rate, infections, psychological stress and cold climate [7]. More recently, Wilkins proposed similar ideas, with a focus on obesity and insulin resistance as the major accelerator [20]. This article argues that the accelerating effects are exerted by a number of risk factors which, acting together via a variety of mechanisms, may all lead to beta cell overload (Fig. 1).

Descriptive epidemiological studies from many parts of the world have shown that the incidence of typel diabetes reaches a peak by the time of puberty in both boys and girls. An early suggestion was that this association was due to the high growth rate during puberty causing a relative increase in insulin need as a result of the effect of growth hormone upon insulin resistance [21], superimposed upon the overall anabolic situation and need for calories. Prospective growth data from a population-based study showed that children who developed diabetes had been growing faster than age-matched controls for many years before the onset of diabetes [22]. This confirmed earlier observations that, at the onset of the disease, children tended to be taller than age-matched healthy children, despite a pre-diagnosis period of insulin deficit [23, 24]. Thus, both puberty and high linear growth in any age group was associated with an increased risk of childhood type 1 diabetes. More recently, several prospective studies have confirmed the association with height and have also shown that increases in all estimates of child growth (height, weight and BMI) are associated with increased risk [25-28] - in particular, early height and weight increase over the first 2 years of life [28]. Obesity has also been proposed to be a predictor of type 1 diabetes over
Fig. 1 Accelerating factors of beta cell destruction: the overload hypothesis

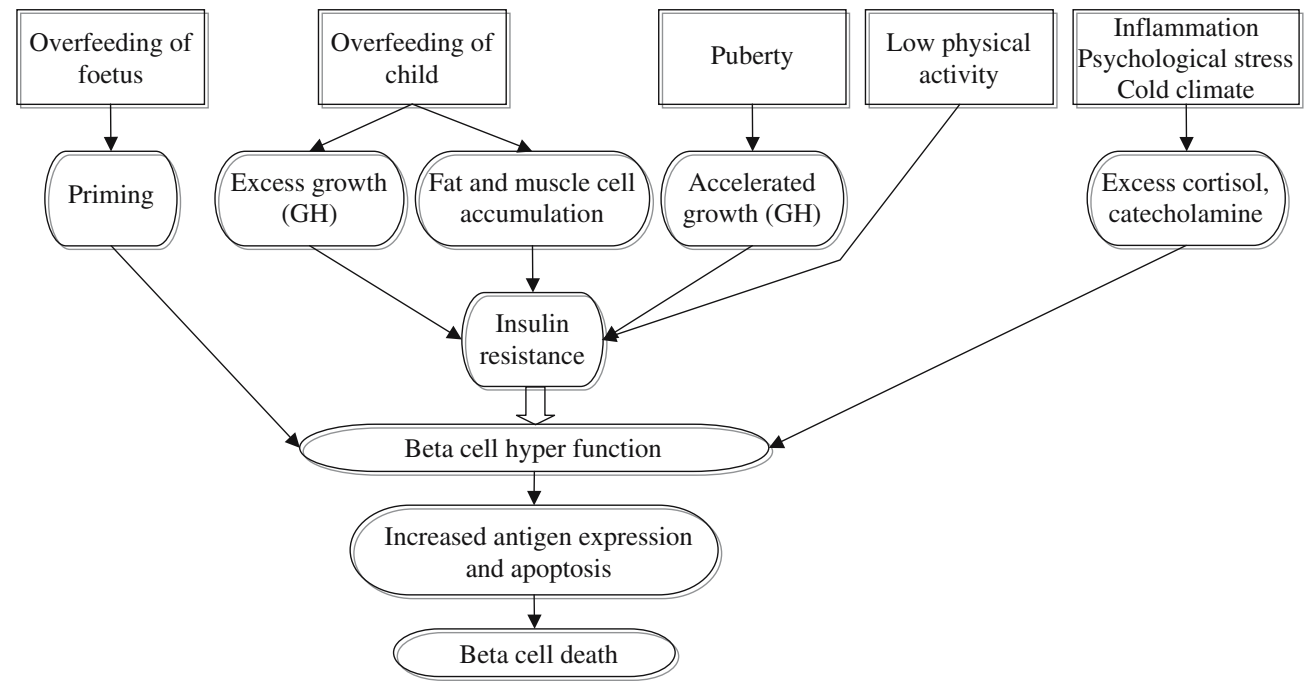


and above increased linear growth [27]. A multicentre prospective study involving different European populations confirmed that even small increases in height, weight and BMI were significant risk determinants when adjusted for age, sex and centre effects [28]. No significant heterogeneity was shown over different contributing centres in Europe. In the European case-control study, as much as $24 \%$ of risk was attributable to child weight at 12 24 months of age ( $>1 \mathrm{SD})$ and $17 \%$ was attributable to height and BMI ( $>1$ SD) after 12-24 months. Since growth depends on genetic, nutritional and hormonal factors, we cannot exclude the possibility that the association between high growth rate and childhood diabetes results from a common genetic trait, e.g. the insulin gene (INS) variable number of tandem repeats (VNTR) locus may be associated with both type 1 diabetes and child growth [29]. However, both height and BMI standard deviation scores were independently predictive of diabetes when simultaneously included in a logistic regression analysis [28], which speaks more in favour of nutrition as a common denominator.

The most important determinant of both child growth and weight gain is nutrition. Despite difficulties in estimating the quantitative intake of calories and nutrients, reports indicate that children who go on to develop diabetes have been overfed in terms of total calories and all categories of nutrients [30] before onset of disease, when taking body size into account [31]. A high intake of monosaccharides and disaccharides seemed particularly associated with risk [31].

Major life events have been associated with onset of type 1 diabetes [32], possibly mediated by increased levels of stress hormones, which are also increased in all conditions involving inflammation. Non-specific infections are well known to increase insulin need and to be associated with disease onset [33]. Since infections in northern latitudes are generally more abundant in autumn and winter, this is a possible explanation for seasonality of disease onset [34]. Cold climate will also increase insulin need [35], and may in part account for the so-called north-south gradient of type 1 diabetes.

In summary, several environmental factors other than obesity may lead to increased insulin need and thus accelerate or precipitate disease onset. Overfeeding children will lead to both acute and chronic overload of the beta cell, since overfeeding leads to increased fat cell mass and increased linear growth mediated by increased growth hormone levels, all of which contribute to insulin resistance. Height, weight and BMI-concomitant estimates of child growth - may account for around $20 \%$ of childhood type 1 diabetes.

\section{Possible mechanisms}

There is good evidence that overloading the beta cell is associated with insulin secretory abnormalities in type 2 diabetes, and that deterioration of beta cell function may in part be caused by accelerated apoptosis [36]. Apoptosis is also an important feature of beta cell death in type 1 diabetes, and a recent review of experimental data concluded that immunological, inflammatory and metabolic signals combine to cause it [37]. If, for example, in vitro cytokine toxicity is increased in a hyperglycaemic milieu [38], the slow self-perpetuating beta cell destruction proposed by the Steno group should be accelerated by overload. Hyperglycaemia will also increase GAD expression on the beta cell surface and possibly upregulate immune activity [39]. Experimental studies thus provide at least two possible mechanisms to explain an overload effect on the rate of beta cell destruction.

\section{Foetal priming of diabetes}

The intriguing reports of Barker and associates have led to the hypothesis, now widely accepted, that insulin resistance and type 2 diabetes are primed by in utero starvation, thus reviving the older concept of foetal priming of disease. A large prospective study allowed us to analyse the association between birthweight adjusted for gestational age and the risk of type 1 diabetes [40]. Children with a low birthweight by gestational age had a lower risk of childhood type 1 diabetes, whereas those with a high birthweight for gestational age had an increased risk. The trend for the association between intrauterine growth and diabetes risk was almost linear when adjusted for maternal diabetes. Similar findings have been reported from Norway [41] and are supported by observations from the European casecontrol study [28]. It has been suggested that birthweight may be determined by HLA specificities that also confer risk of type 1 diabetes, but the results of population-based studies are conflicting. One study showed an inverse relationship between birthweight and high-risk HLA specificities [42], whereas another showed a weak (odds ratio $=1.2$ ) but significant positive correlation with some HLA high-risk genes, and a positive correlation with a protective HLA genotype [43].

It thus seems as if the overfed foetus is liable to type 1 diabetes, whereas the starved foetus is prone to type 2 . The discrepancy might be explained on the grounds that the beta cells in an overfed foetus may develop a beta cell phenotype more liable to apoptosis and necrosis and with a different glucose responsiveness [44]. Foetal starvation also has effects on the periphery predisposing to insulin resistance. The rapidly developing fields of nutrigenomics and epigenetics $[45,46]$ have offered fascinating insights into the ways in which early nutrition may have fundamental and long-lasting effects upon human development, and are of clear relevance to the epidemics of both type 1 and type 2 diabetes.

In summary, increased birthweight caused by overfeeding in utero may contribute to the overload effect of subsequent exposures by priming beta cell responsiveness. It may also alter beta cell liability to apoptosis and necrosis. 


\section{The overwealth dilemma-what can we do?}

Of the proposed accelerating factors, only child growth and weight and foetal priming would be compatible with a steady incidence trend and a lower age at onset. Birthweight and childhood growth are well-recognised estimates of overall wealth and lifestyle habits, both between and within ethnic groups. In Sweden we still experience increases in gross national product (GNP), and these increases parallel those in both birthweight and overweight [47], with a strong correlation between the change in GNP and the incidence of childhood diabetes in Sweden over a 20 -year period [3]. An ecological analysis over a wide range of incidence rates of type 1 diabetes and covering more than 40 population-based registers from different European centres showed a strong correlation between the incidence of childhood-onset diabetes and official estimates of GNP [48]. It is thus tempting to suggest that lifestyle habits associated with wealth and overfeeding contribute to the increasing incidence of childhood diabetes in many countries. How can we handle this situation?

One approach would be to treat children with pharmacological agents such as metformin, but this is not a harmless drug and there is little experience with its use in the very young. A high proportion of children treated in such studies would not progress to diabetes, while it seems likely that no more than $20 \%$ of childhood-onset cases can be attributed to increases in insulin resistance alone. From a more philosophical perspective, one could question why we should aim to introduce possible lifelong medication in children to prevent one of the consequences of overfeeding, when we could focus on the overfeeding itself.

A better way to go, at present, would be to promote large population-based intervention programmes that target the pregnant mother and young families, and aim to change eating habits and sedentary lifestyle. Intervention programmes leading to significant changes in eating patterns and physical activity are successful in preventing type 2 diabetes in adults [49]. Nutrition counselling given to parents when the child is 7 months of age and repeated at 6-monthly intervals up to the age of 7 years has been shown to change the eating habits of the children compared with those of control children whose parents did not receive the intervention [50].

Primary prevention strategies aimed at the young families and commencing in pregnancy might be even more effective, since the motivation for changing lifestyle for the benefit of the expected child should be high. Such intervention appears harmless, may reach all children at risk in a population, and avoids the costs of repeated mass screening and the problems associated with application of predictive markers. The benefits of such interventions should extend well beyond their likely influence upon future rates of diabetes.

\section{References}

1. Onkamo P, Vaaananen S, Karvonen M, Tuomiletho J (1999) Worldwide increase in incidence of type 1 diabetes: the analysis of the data on published incidence trends. Diabetologia 42: $1395-1403$

2. EURODIAB ACE Study Group (2000) Variation and trends in incidence of childhood diabetes in Europe. Lancet 355:873876

3. Dahlquist GG, Mustonen L for the Swedish Childhood Diabetes Study Group (2000) Analysis of 20 years of prospective registration of childhood onset diabetes - time trends and birth cohort effects. Acta Paediatr 89:1231-1237

4. Pundziute-Lyckå A, Dahlquist GG, Nyström L et al (2002) The incidence of Type 1 diabetes has not increased but shifted to a younger age at diagnosis in the 0-34 years group in Sweden 1983 to 1998 . Diabetologia 45:783-791

5. Weets I, De Leeuw IH, Du Caju MV et al (2002) The incidence of type 1 diabetes in the age group 0-39 years has not increased in Antwerp (Belgium) between 1989 and 2000: evidence for earlier disease manifestation. Diabetes Care 5:840-846

6. Gale EAM (2005) Spring harvest? Reflections on the rise of type 1 diabetes. Diabetologia DOI: 10.1007/s00125-005-0028-z

7. Dahlquist GG (1995) Environmental risk factors in human type 1 diabetes - an epidemiological perspective. Diabetes Metab Rev 11:37-46

8. Tarn AC, Thomas JM, Dean BM et al (1988) Predicting insulindependent diabetes. Lancet i:845-850

9. Riley WJ, MacLaren NK, Krischer J et al (1990) A prospective study of the development of diabetes in relatives of patients with insulin-dependent diabetes. N Engl J Med 323:1167-1172

10. Palmer JP, McCulloch DK (1991) Prediction and prevention of IDDM-1991. Diabetes 40:943-947

11. Millward BA, Alviggi L, Koskins PJ et al (1986) Immune changes associated with insulin-dependent diabetes may remit without causing diabetes: a study in identical twins. Br Med J 292:793-796

12. Tun RYM, Peakman M, Alviggi L et al (1994) The importance of persistent cellular and humoral immune changes in the prediabetic period: a prospective identical twin study. Br Med J 308:1063-1068

13. Kulmala P, Savola K, Reijonen H et al (2000) Genetic markers, humoral autoimmunity, and prediction of type 1 diabetes in siblings of affected children. Diabetes 49:48-58

14. Williams AJ, Bingley PJ, Moore WP, Gale EA; ENDIT Screening Group (2002) Islet autoantibodies, nationality and gender: a multinational screening study in first-degree relatives of patients with Type I diabetes. Diabetologia 45:217-223

15. Rossini AA, Greiner DL, Friedman HP, Mordes JP (1993) Immunopathogenesis of diabetes mellitus. Diabetes Rev 1:43-75

16. Atkinson MA, Eisenbarth GS (2001) Type 1 diabetes: new perspectives on disease pathogenesis and treatment. Lancet 358:221-229

17. Jun HS, Yoon JW (2003) A new look at viruses in type 1 diabetes. Diabetes Metab Res Rev 19:8-31

18. Gerstein HC (1994) Cow's milk exposure and type I diabetes mellitus. Diabetes Care 17:13-19

19. Dahlquist G (1993) Nutritional Factors. In: Leslie RDG (ed) Causes of diabetes: genetic and environmental factors. Wiley, Chichester, pp 125-132

20. Wilkin TJ (2001) The accelerator hypothesis: weight gain as the missing link between Type I and Type II diabetes. Diabetologia 44:914-922

21. Amiel SA, Sherwin RS, Simonson DC, Lauritano AA, Tamborlane WV (1986) Impaired insulin action in puberty. A contributing factor to poor glycemic control in adolescents with diabetes. N Engl J Med 315:215-219

22. Blom L, Persson LÅ, Dahlquist G (1992) A high linear growth is associated with an increased risk of childhood diabetes mellitus, Diabetologia 35:528-533 
23. Drayer NM (1974) Height of diabetic children at onset of symptoms. Arch Dis Child 49:616-662

24. Songer TJ, LaPorte RE, Tajima N et al (1986) Height at diagnosis of insulin-dependent diabetes in patients and their nondiabetic family members. Br Med J 292:1419-1422

25. Johansson C, Samuelsson U, Ludvigsson J (1994) A high weight gain early in life is associated with an increased risk of Type I (insulin-dependent) diabetes mellitus. Diabetologia 37: 91-94

26. Hypponen E, Kenward MG, Virtanen SM et al (1999) Infant feeding, early weight gain, and risk of type I diabetes. Childhood Diabetes in Finland (DiMe) Study Group. Diabetes Care 22:1961-1965

27. Hypponen E, Virtanen SM, Kenward MG, Knip M, Åkerblom H (2000) Obesity, increased linear growth, and risk of type 1 diabetes in children. Diabetes Care 23:1755-1760

28. Patterson C, Dahlquist G, Soltesz G for the EURODIAB substudy 2 study group (2002) Rapid early growth is associated with increased risk of childhood type 1 diabetes in various European populations. Diabetes Care 25:1755-1760

29. Undlien DE, Bennett ST, Todd JA et al (1995) Insulin gene region-encoded susceptibility to IDDM maps upstream of the insulin gene. Diabetes 44:620-625

30. Dahlquist GG, Blom LG, Persson LA, Sandström AI, Wall SG (1990) Dietary factors and the risk of developing insulin dependent diabetes in childhood. Br Med J 300:1302-1306

31. Pundziute-Lyckå A, Persson LÅ, Cedermark G et al (2004) Diet, growth and the risk for type 1 diabetes in childhood: a matched case-referent study. Diabetes Care 12:2784-2789

32. Hägglöf B, Blom L, Dahlquist G, Lönnberg G, Sahlin B (1991) The Swedish childhood diabetes study: indications of severe psychological stress as a risk factor for type1 (insulindependent)diabetes mellitus in childhood. Diabetologia 34: 757-762

33. Blom L, Nyström L, Dahlquist G (1991) The Swedish childhood diabetes study: vaccinations and infections as risk determinants for diabetes in childhood. Diabetologia 34:176181

34. Gamble DR, Taylor KW (1969) Seasonal incidence of diabetes mellitus. Br Med J 3:631-633

35. Suarez L, Barrett-Connor E (1982) Seasonal variation in fasting plasma glucose levels in man. Diabetologia 22:250-253

36. Grill W, Björklund A (2001) Overstimulation and beta cell function. Diabetes 50(Suppl):58-63

37. Eizirik DL, Darville MI (2001) $\beta$-Cell apoptosis and defense mechanisms: lessons from type 1 diabetes. Diabetes 50(Suppl 1): 64-69
38. Mandrup-Poulsen T (1996) The role of interleukin-1 in the pathogenesis of IDDM. Diabetologia 39:1005-1029

39. Björk E, Kampe O, Karlsson FA et al (1992) Glucose regulation of the autoantigen GAD65 in human pancreatic islets. J Clin Endocrinol Metab 75:574-576

40. Dahlquist G, Bennich SS, Kallen B (1996) Intrauterine growth pattern and risk of childhood onset insulin dependent (type I) diabetes: population based case-control study. Br Med J 313: 1174-1177

41. Stene LC, Magnus P, Lie RT, Sovik O, Joner G and the Norwegian Childhood Diabetes Study Group (2001) Birth weight and childhood onset type I diabetes: population based cohort study. Br Med J 322:889-892

42. Stene L, Rolv PM, Lie T, Sovik O, Joner G and the Norwegian Childhood Diabetes Study group (2001) Birth weight and childhood onset type 1 diabetes: population-based cohort study. Br Med J 322:889-892

43. Larsson HE, Lynch B, Lernmark B, Nilsson A, Hansson G, Almgren P, Lernmark Å, Ivarsson S-A; DiPiS Study Group (2005) Diabetes-associated HLA genotypes affect birthweight in the general population. Diabetologia 48:1484-1491

44. Pipeleers D, Hoorens A, Marichal-Pipeleers M, Van de Casteele M, Bouwens L, Ling Z (2001) Role of pancreatic $\beta$-cell death. Diabetes 50(Suppl. 1):52-57

45. Gallou-Kabani C, Junien C (2005) Nutritional epigenomics of metabolic syndrome. New perspectives against the epidemic. Diabetes 54:1899-1906

46. Srinivasan M, Aalinkeel R, Song F, Patel MS (2003) Programming of islet functions in the progeny of hyperinsulinemic/obese rats. Diabetes 52:984-990

47. Mårild S, Bondestam M, Bergström R, Ehnberg S, Hollsing A Albertsson-Wikland K (2004) Prevalence trends of obesity and overweight among 10-year-old children in western Sweden and relationship with parental body mass index. Acta Paediatr 93: $1588-1595$

48. Patterson CC, Dahlquist G, Soltész G, Green A on behalf of the EURODIAB ACE Study Group (2001) Is childhood-onset Type 1 diabetes a wealth-related disease? An ecological analysis of European incidence rates. Diabetologia 44(Suppl 3): B9-B16

49. Eriksson J, Lindström J, Tuomilehto J (2001) Potential for the prevention of type 2 diabetes. Br Med Bull 60:183-199

50. Rasanen M, Niinikoski H, Keskinen S et al (2004) Impact of nutrition counselling on nutrition knowledge and nutrient intake of 7- to 9-y-old children in an atherosclerosis prevention project. Eur J Clin Nutr 58:162-172 